\title{
EDITORIAL
}

\section{Longitudinal transactional models of development and psychopathology}

\author{
LESLIE D. LEVE $^{a}$ AND DANTE CICCHETTI ${ }^{b}$ \\ ${ }^{a}$ University of Oregon Prevention Science Institute; and ${ }^{b}$ University of Minnesota Institute of Child Development
}

Development is necessarily the result of the interdependence, coaction, and/or codetermination among multiple levels of influence over time (Gottlieb, 2001). In 1975, Sameroff and Chandler proposed a transactional model of development that recognized the importance of the transacting genetic, constitutional, neurobiological, biochemical, psychological, and sociological factors in the determination of behavior, and that stated that those factors change through their dynamic transaction. Sameroff and Chandler's (1975) model takes into account the interrelationships among dynamic systems and the processes by which compensatory, self-regulating tendencies are initiated whenever higher level monitors detect deviances in a system (Sameroff, 2000; Waddington, 1966). An implication of the transactional model is that the continued manifestation of maladaptation depends on environmental support, whereas the child's reciprocal characteristics partially determine the nature of the environment. Thus, an all-encompassing and theoretically meaningful model of development must yield a formulation of the developmental process that can embrace both stability and change. It must transcend the multifaceted ways in which constitutional, organismic, and environmental factors transact to affect development.

By focusing on longitudinal transactional models of development and psychopathology, this Special Issue extends the rich history in Development and Psychopathology of understanding the multiple mechanisms and processes whereby children develop psychopathology or are protected from its development (Cicchetti \& Dawson, 2002). In 2010, a two-part special issue on developmental cascades examined the cumulative effects of influences across levels and areas of functioning, while testing developmental cascade models of change (Masten \& Cicchetti, 2010). The articles in that special issue provided new insights into how problems in one domain of

Address correspondence and reprint requests to: Leslie D. Leve, Prevention Science Institute, University of Oregon, Eugene, OR 97403-6217; E-mail: leve@ uoregon.edu; or Dante Cicchetti, Institute of Child Development, University of Minnesota, 51 East River Road, Minneapolis, MN 55455; E-mail: cicchett@umn.edu. functioning might cascade into other domains of functioning. A more recent special issue devoted to multilevel approaches for understanding the development of antisocial behavior (Burnette \& Cicchetti, 2012) included articles describing multiple method, multiple level, longitudinal designs focused specifically on understanding the complex influences on antisocial behavior. These special issues helped answer critical questions in the field regarding the multiple transactional influences on the development of psychopathology. The current Special Issue builds on these advances and focuses specifically on longitudinal models that cut across multiple developmental periods and include three or more time points of data collection, to expand the understanding of transactional models across infancy, childhood, adolescence, and adulthood and examine a larger window of development within each study.

The call for longitudinal models of development, such as those included in this Special Issue, has taken on a global profile, with two recent initiatives led by the National Institutes of Health. Funded in 2015, the Longitudinal Study of Adolescent Brain and Cognitive Development is recruiting 10,000 healthy children age 9-10 and is following them over 10 years into early adulthood, to measure brain maturation in the context of social, emotional, and cognitive development. Similarly, the Environmental Influences on Child Health Outcomes Program at the National Institutes of Health will support multiple longitudinal studies using existing study populations to investigate environmental exposures, including physical, chemical, biological, social, behavioral, natural, and built environments, on child health and development. These two national initiatives will yield rich longitudinal data sets that are ripe for the incorporation of longitudinal transactional models that examine the development of psychopathology across multiple developmental periods and use multilevel sources of data. However, it will be a decade before these large-scale national initiatives are completed and their findings shared with academic and professional audiences. The articles in this Special Issue lay the groundwork for this national work by testing novel hypotheses about the transactional nature of development across time and across 
environmental and biological contexts by using longitudinal data sets that cut across multiple developmental periods to study development over a decade or more in many cases.

One of the key themes illustrated by the longitudinal analyses presented in the articles in this Special Issue is the great potential for recovery and resilience among children exposed to varied forms of adversity, regardless of whether the adversity stems from experiences in the families that the children have grown up in, their neighborhood environments, their peer networks, their genetic makeup, or in all likelihood, a complex combination of these influences. Further, consistent with bidirectional, transactional models of risk and resilience (Cicchetti \& Curtis, 2007), the articles in this issue provide evidence that children are not simply passive recipients of their environments, but rather, they contribute to their own development in both passive and active ways, by eliciting behaviors from others and by selecting people and contexts within which to interact (e.g., Pardini, 2008; Scarr \& McCartney, 1983). Further, several papers in this Special Issue use randomized, controlled trial designs to gain further insights into causal mechanisms underlying the development of psychopathology over time. Randomized control trial designs are considered the gold standard for testing causal mechanisms of development and psychopathology and identifying pathways to healthy adjustment, but the articles in this issue add an additional feature: a long-term developmental design. This helps address the significant question in the extant literature of whether programs designed to prevent or reduce psychopathology have sustainable effects in the long term or whether intermediary processes are at play over time that work to either sustain or undermine intervention effects. The longterm intervention follow-up studies in this Special Issue help fill this critical gap in the field in this regard.

Finally, the articles in the Special Issue contribute in important ways to methodological advances relevant to testing mod-

\section{References}

Burnette, M. L., \& Cicchetti, D. (2012). Multilevel approaches toward understanding antisocial behavior: Current research and future directions. Development and Psychopathology, 24, 703-704.

Cicchetti, D., \& Curtis, W. J. (2007). Multilevel perspectives on pathways to resilient functioning. Development and Psychopathology, 19, 627-629.

Cicchetti, D., \& Dawson, G. (2002). Multiple levels of analysis. Development and Psychopathology, 14, 417-420.

Enders, C. K. (2010). Applied missing data analysis (methodology in the social sciences). New York: Guilford Press.

Gottlieb, G. (2001). Individual development and evolution: The genesis of novel behavior. New York: Oxford University Press.

MacKinnon, D. P. (2008). Introduction to statistical mediation analysis. New York: Routledge.

MacKinnon, D. P., Lockwood, C. M., \& Williams, J. (2004). Confidence limits for the indirect effect: Distribution of the product and resampling methods. Multivariate Behavioral Research, 39, 99-128.

Masten, A. S., \& Cicchetti, D. (2010). Developmental cascades. Development and Psychopathology, 22, 491-495.

Millsap, R. E. (2011). Statistical approaches to measurement invariance. New York: Routledge.

Pardini, D. A. (2008). Novel insights into longstanding theories of bidirectional parent-child influences: Introduction to the special section. Journal of Abnormal Child Psychology, 36, 627-631. els of development and psychopathology. The field has made significant strides over the last decade in developing methodological techniques and approaches to conduct strong tests of longitudinal transactional models of development. This is important because stringent tests of longitudinal models of development and psychopathology should simultaneously consider continuity in behavior, mediational or indirect effects, reciprocal relationships, as well as covariates and potential moderating variables. Thus, longitudinal transactional studies can present serious methodological challenges, particularly when the presentation or expression of psychopathology changes across development, as in the transition from oppositional behavior, to conduct problems, to antisocial behavior. The papers in this Special Issue are exemplary in their incorporation of complex methods for testing mediating and indirect pathways longitudinally (MacKinnon, 2008; MacKinnon, Lockwood, \& Williams, 2004; Millsap, 2011; Preacher \& Hayes, 2008; Taylor, MacKinnon, \& Tein, 2008; Tofighi \& MacKinnon, 2011) and proposing new methods that account for the fact that transactional mechanisms can produce excess stability in an outcome domain, above and beyond autoregressive processes (see in this issue, Roisman, Fraley, Haltigan, Cauffman, \& Booth-LaForce, 2016). Methods for handling missing data (Enders, 2010), another pesky methodological challenge in longitudinal research, are also rigorously applied across the articles in this Special Issue.

There is a continued need to pursue the development of new theories, methods, and approaches to test complex transactional longitudinal models, and stay abreast of the rapid advances in the measurement of problem behavior if we are to better understand the pathways to, and prevention of, psychopathology. By studying multiple developmental periods and utilizing novel analytic approaches, the articles in this Special Issue represent a highly promising foundation for future longitudinal research in development and psychopathology.

Preacher, K. J., \& Hayes, A. F. (2008). Asymptotic and resampling strategies for assessing and comparing indirect effects in multiple mediator models. Behavior Research Methods, 40, 879-891.

Roisman, G. I., Fraley, C. R., Haltigan, J. D., Cauffman, E., \& Booth-LaForce, C. (2016). Strategic considerations in the search for transactional processes: Methods for detecting and quantifying transactional signals in longitudinal data. Development and Psychopathology, 28, 791-800.

Sameroff, A. J. (2000). Developmental systems and psychopathology. Development and Psychopathology, 12, 297-312.

Sameroff, A. J., \& Chandler, M. J. (1975). Reproductive risk and the continuum of caretaking causality. In F. D. Horowitz (Ed.), Review of child development research (Vol. 4, pp. 187-244). Chicago: University of Chicago Press.

Scarr, S., \& McCartney, K. (1983). How people make their own environments: A theory of genotype $\rightarrow$ environment effects. Child Development, $54,424-435$.

Taylor, A. B., MacKinnon, D., \& Tein, J.-Y. (2008) Test of the three path mediated effect. Organization Research Methods, 11, 241-269.

Tofighi, D., \& MacKinnon, D. P. (2011). RMediation: An R package for mediation analysis confidence intervals. Behavior Research Methods, $43,692-700$.

Waddington, C. H. (1966). Principles of development and differentiation. New York: Macmillan. 